\title{
Collectively Building a Sustainable Sharing Economy Based on Trust and Regulation
}

\author{
Elfriede Penz ${ }^{1, *}$, Barbara Hartl ${ }^{2,3}$ and Eva Hofmann ${ }^{2}$ \\ 1 Department of Marketing, Institute for International Marketing Management, Vienna University of Business \\ and Economics, Welthandelsplatz 1, A-1020 Vienna, Austria \\ 2 Competence Center for Empirical Research Methods, Vienna University of Business and Economics, \\ Welthandelsplatz 1, A-1020 Vienna, Austria; barbara.hartl@wu.ac.at (B.H.); eva.hofmann@wu.ac.at (E.H.) \\ 3 Institute of Organization and Global Management Education, Johannes Kepler University, \\ Altenberger Str. 69, A-4040 Linz, Austria \\ * Correspondence: elfriede.penz@wu.ac.at; Tel.: +43-1-31-336-5102
}

Received: 15 October 2018; Accepted: 16 October 2018; Published: 18 October 2018

check for updates

\begin{abstract}
The articles in this Special Issue on the sharing economy's role in fostering sustainability comprise eight contributions to answer how trust and regulation shape relations of providers and consumers. We identify indispensable aspects of the sharing economy to show its potential in fostering sustainability. This is in some contrast to existing definitions and applications of sharing economy business models, which do not place sustainability in their focus. The studies employ a variety of methods, covering quantitative and qualitative research to investigate building of communities on the consumer side, as well as trust-building and implementation of regulations in the interaction between providers and consumers in Asia and Europe. Some areas in the sharing economy foster sustainability, some foster social cohesion and in the end build social capital, but others focus at first sight on convenience and lifestyle.
\end{abstract}

Keywords: sharing economy; sustainable lifestyle; trust; regulation; provider and consumer interaction

\section{Introduction}

Sustainable consumption is a major issue in the marketplace in the beginning of the 21st century [1-4], as over-consumption and exploitation of resources are made responsible for many environmental problems [5]. Adopting a sustainable lifestyle can reduce exploitation of natural resources. Part of such a sustainable lifestyle is to offer and share underutilized resources, an increasingly popular way of consuming and equally significant research topic in different disciplines. This development nurtures the hope that sustainability can be raised, be it due to resource efficiency or simply reductions in waste. In the sharing economy, instead of buying goods and owning them, consumers gain temporary access to goods they need. Current research acknowledges the role of technology as facilitator of modern-day sharing [6], discusses antecedents of participating in the sharing economy [7], and highlights problems within the sharing economy, such as racial discrimination [8].

However, while the sharing economy's principles can be found in almost all business areas, including tourism (e.g., Airbnb), entertainment (e.g., public bookshelves), food (e.g., food co-ops), and transport (e.g., BlaBlaCar), an increasingly sober stance regarding their potential to increase sustainability has also emerged [9]. One perspective is to criticize the missing effect on mainly ecological sustainability, another is the monetarization of human effort and consumer assets, seen in Uber or Airbnb, and the description of the platform economy as disruptive technology [10]. Sustainability is often defined in terms of social, economic, and environmental dimensions. However, 
there are views that these dimensions are more integrated and suggest looking at socio-economic dimensions of "human aspirations for a better life" [11], (p. 3439), such as welfare or well-being.

We focus on these issues in this Special Issue and summarize the contributions by first discussing the conceptual basis of the relation between the sharing economy and sustainability. Second, we group and describe the respective articles. Eventually, the sharing economy's role in fostering sustainability will be discussed.

This Special Issue aimed to explore and explain how, why, and when a sustainable lifestyle is adopted and participation in the sharing economy becomes key. It called for research that shows how this affects businesses, platforms, and consumers, and which insights for businesses, legislators, and researchers result-for instance, regarding how to design and regulate the sharing economy.

The collection of articles in this Special Issue address these aims. They draw from literature that includes the idea of sustainability in the description of the sharing economy [12], in particular Frenken and Schor provide a summary on environmental impact of the sharing economy [13].

How sharing economy models and sustainability (sustainable sharing economy, SSE) correspond conceptually in the collected articles is summarized in Table 1. The authors in this Special Issue addressed in particular three phases of consumer demand and consumption, which show how the sharing economy can contribute to sustainable consumption. First, (i) through sharing products less demand is created which would result in lower production. Second, (ii) sharing products means using already produced goods more and longer, using them interactively as a community which results in a lower ecological footprint. Third, (iii) product disposal is avoided.

Table 1. Aspects of the sustainable sharing economy (SSE).

\begin{tabular}{lcc}
\hline Sustainability Related Aspects of Sharing & Based on, e.g., & Used by Authors in This Special Issue \\
\hline (i) Producing less & {$[14]$} & {$[15]$} \\
(ii) Idle capacity and under-utilized physical assets & {$[16,17]$} & {$[18-20]$} \\
(ii) Resource efficiency through using rather than owning & {$[21,22]$} & {$[19,23]$} \\
(iii) Reduce waste & {$[13]$} & {$[18]$} \\
(ii) Extended use pattern & {$[24-26]$} & {$[27,28]$} \\
(ii) Low ecological footprint/low carbon & {$[29]$} & {$[19,23,30]$} \\
(ii) Own less, interact more, build social capital & & \\
\hline
\end{tabular}

In particular, respective aims were to investigate the relationship between sustainability and the sharing economy, exploring (the buildup of) consumer communities engaging in the sharing economy, analyzing challenges for organizations in the sharing economy with regard to trust-building and regulation, and designing of sustainable virtual environments as a market place of the sharing economy. In order to support sustainability, certain issues in the sharing economy need to be discussed. The articles in this Special Issue addressed especially two issues empirically: (i) exploring consumer communities engaging in the sharing economy, and (ii) challenges for organizations in the sharing economy with regard to trust-building and regulation.

\section{Engagement in and Challenges for the Sustainable Sharing Economy}

\subsection{Consumer Communities in the Sharing Economy}

Vaskelainen and Piscicelli [19] investigated the question of how different online and offline communities (producer, consumer, value-based, relational, geographic) are relevant to the functioning of sharing economy platforms. In their qualitative content analysis of archival and interview data with UK platform users, it turned out that the analyzed (unsuccessful) goods-sharing platform mainly served relational (offline) communities, which connect individuals by interest or profession by means of usually high trust among community members.

In order to investigate what kind of regulations create conditions for cooperation in sharing communities, such as community gardens, Sabitzer et al. [20] conducted a qualitative study followed by a questionnaire with Austrian respondents. Findings indicate that regulations are perceived as 
useful to prevent conflicts and free-riding, and cooperation should be encouraged rather than forced. So-called harsh forms of power lead to greater conflicts, while soft forms of power lead to higher trust in the community and better conflict resolution.

The paper by Kang and $\mathrm{Na}$ [30] tests the assumption that the sharing economy's social capital in the form of enabling social relationships and social commitment (based on exchange activity, importance of relationship and emotional connection, pleasure or self-fulfillment) provides a competitive advantage for companies. This leads to continuing commitment of Korean consumers to engage in the sharing economy. Based on this, it is suggested to design group benefits, for example, by implementing standards or rules in the group (structure) and to increase the quality of the relationships through interaction by creating mutual benefits.

\subsection{Trust-Building and Regulation as Mechanisms in the Sharing Economy}

For the sharing economy, the relationship between providers and consumers, and consequently trust-building measures and adequate regulations, such as reputation systems, are crucial. Trust is important in the sharing economy, where traditional market rules are abrogated and respective legislation has not been generated yet. If the interaction between providers and consumers cannot be regulated comprehensively with trust, regulations become essential [31].

In their paper, ter Huurne and colleagues [23] investigate the effect of reputation of the seller on trust between seller and buyer in sharing platforms by means of a longitudinal analysis of meals shared. They choose a meal sharing platform, which relies primarily on social exchange to show that trust (measured via price and sales) increases. In addition, they also show that information about the seller (profile including picture) outweighs the effects of reputation. Thus, using reputation systems in sharing platforms increases sharing, however, if reputation is still low, seller information such as their profiles might offset this. Users should be asked to rate the seller to build reputation.

To understand trust-building mechanisms better, Wu and Shen [28] undertook a survey of Chinese Airbnb users. Moderated by cultural values along Hofstede's cultural dimensions [32], three modes of trust-building were found to exist. In more detail, institutional trust, i.e., mechanisms set up by providers, is found to be the basis for trust in the product (e.g., perceived as reliable) and between individual parties (interpersonal trust). The low individualism scores strengthen these links and authors conclude that trust-building in the sharing economy is more effective in China.

In a similar vein, Liu and Yang [27] investigated the (technology) acceptance model (TAM) of sharing in China using the example of bicycle sharing. By employing an online survey, they particularly looked at how norms (organizational and personal level), trust, and TAM variables such as perceived ease of use and usefulness, impact behavioral intentions. Trust, which is influenced by subjective norms, indirectly impacts intention. TAM is a useful model to be applied in the sharing economy. Imitating others (herd behavior), proved to be effective for bicycle-sharing use intention, especially for men, who would more likely change their behavior.

A detailed look at how the perception of the concept sharing ("sharewashing") leads to trust in consumers, and how risk perception and confusion mediate this relation, is taken by Hawlitschek and colleagues [18], who ran an online survey with German millennials. They found that if consumers think that sharing platforms misleadingly portray their activities as social or ecological, they trust less in the performance.

The paper by Amasawa and colleagues [15] aimed to develop effective interventions for environmental behavior involving product sharing, exemplified by laundromat sharing in Japan. In their in-depth interview and web-survey studies, they analyzed consumer decision processes and suggest a model that outlines triggers and influences on shifting to the more environmental option of washing clothes (laundromat sharing). Utility, i.e., accessibility, as well as maximizing privacy, turned out to be vital. 


\section{Discussion}

The eight articles in this Special Issue provide suggestions for how to collectively build a sustainable sharing economy (SSE) based on trust and regulation in provider-consumer interactions. The covered areas of sharing relate to mobility, space, food, and goods, and the geographical context of presented research is Asia, i.e., Japan [15], China [27,28], Korea [30], and Europe, i.e., the Netherlands [23], UK [19], Germany [18], and Austria [20]. While this does not represent all areas of the sharing economy and is not applicable to all areas of the world, the conclusions drawn from the research may help in spotlighting the potential of the sharing economy to foster sustainability.

Exchange structures, which are reflecting a society's belief structure and marketplace actors, are the dominant social paradigm [33] but are faced with alternatives, such as sharing goods instead of monetary exchange. In addition, sustainability is often defined in terms of three dimensions: social, economic, and environmental, but there are views that consider these dimensions as more integrated and suggest looking at socio-economic dimensions of "human aspirations for a better life" [11], (p. 3439), such as welfare or well-being. We see an expression of these socio-economic dimensions in the contributions as sharing involves socio-economic sustainability dimensions rather than a single dimension.

Social structures and capital matter in the sharing economy $[19,20,27,30]$. They reflect people's interest in social relationships, and their social commitment and influence from social norms when it comes to sharing. For instance, for people who do not yet engage in organized sharing, cars and bikes would be the most popular goods for sharing amongst family and close friends, but not outside this immediate network [34]. For broad-scale transportation sharing, this means that issues relating to member trust need to be overcome. The article by Liu and Yang [27] provides insights into the user adoption of bicycle sharing.

Physical sharing requires a high concentration of local members to offer real value as a service, which is dependent on the geographical context. The study by Vaskelainen and Piscicelli [19] studied an unsuccessful sharing platform, where the relational (offline) community benefited the most from sharing. It is suggested to explore the meaning of communities as well as routine aspects of sharing in people's lives.

People share also the spaces they live in and shared travel accommodation is in the top ranks [34]. The article by $\mathrm{Wu}$ and Shen [28] studied trust-building mechanisms in the case of Airbnb in China.

Some authors consider Airbnb's growth deferring or abandoning plans for new hotel construction and think that it offers a more sustainable option as it allows increased sharing and optimization of unused space [35]. In addition, all consumers may benefit from economic advantages (e.g., less aggressive hotel room pricing [36]); however, there is some concern about the ecological and social sustainability of accommodation sharing. One suggestion is to avoid the term "sharing" and focus on other aspects such as convenience and functionality [18].

To sum up, some areas in the sharing economy foster sustainability (idle capacity, reduce waste, prevent new production or purchases, lower ecological footprint), some foster social cohesion and in the end build social capital (indirectly foster sustainability according to UN goals of sustainability) but others focus at first sight on convenience (e.g., saving time, co-working), economic benefits (personal monetization, e.g., UBER) and lifestyle (e.g., living space, Airbnb, community gardens). Following a socio-economic definition of sustainability, they all may contribute to "human aspirations for a better life" [11], (p. 3439).

Defining sharing as 'sharing is use' puts emphasis on the environmental benefits. The total number of consumer goods could go down considerably without loss of consumer welfare, due to increased sharing [16].

However, this depends on the institutions, companies, and platforms regulating and designing the sharing economy. "The way online sharing platforms will be governed, how sharing practices will be regulated, and what kind of tax regime will emerge are fundamentally open questions for the 
future jointly shaped by businesses, citizens, and governments at local, national and transnational scales " [16], (p. 2).

Author Contributions: All authors contributed equally to this Editorial.

Funding: This research was funded by grant number P29693-G29 from the Austrian Science Fund (FWF).

Conflicts of Interest: The authors declare no conflict of interest.

\section{References}

1. Banbury, C.; Stinerock, R.; Subrahmanyan, S. Sustainable consumption: Introspecting across multiple lived cultures. J. Bus. Res. 2012, 65, 497-503. [CrossRef]

2. Phipps, M.; Ozanne, L.K.; Luchs, M.G.; Subrahmanyan, S.; Kapitan, S.; Catlin, J.R.; Gau, R.; Naylor, R.W.; Rose, R.L.; Simpson, B.; et al. Understanding the inherent complexity of sustainable consumption: A social cognitive framework. J. Bus. Res. 2013, 66, 1227-1234. [CrossRef]

3. Vermeir, I.; Verbeke, W. Sustainable food consumption: Exploring the consumer "attitude-Behavioral intention" gap. J. Agric. Environ. Ethics 2006, 19, 169-194. [CrossRef]

4. Tanner, C.; Wölfing Kast, S. Promoting sustainable consumption: Determinants of green purchases by Swiss consumers. Psychol. Market. 2003, 20, 883-902. [CrossRef]

5. Piscicelli, L.; Cooper, T.; Fisher, T. The role of values in collaborative consumption: Insights from a productservice system for lending and borrowing in the uk. J. Clean. Prod. 2015, 97, 21-29. [CrossRef]

6. Hellwig, K.; Sahakian, M.; Morhart, F. Societal factors and the emergence of the sharing economy. In The Rise of the Sharing Economy: Exploring the Challenges and Opportunities of Collaborative Consumption; ABC-Clio, LLC: Santa Barbara, CA, USA, 2018; pp. 51-74.

7. Böcker, L.; Meelen, T. Sharing for people, planet or profit? Analysing motivations for intended sharing economy participation. Environ. Innov. Soc. Trans. 2017, 23, 28-39. [CrossRef]

8. Edelman, B.; Luca, M.; Svirsky, D. Racial discrimination in the sharing economy: Evidence from a field experiment. Am. Econ. J. Appl. Econ. 2017, 9, 1-22. [CrossRef]

9. Martin, C.J. The sharing economy: A pathway to sustainability or a nightmarish form of neoliberal capitalism? Ecol. Econ. 2016, 121, 149-159. [CrossRef]

10. Katz, V. Regulating the sharing economy. Berkeley Technol. Law J. 2015, 30, 1067.

11. Kuhlman, T.; Farrington, J. What is sustainability? Sustainability 2010, 2, 3436-3448. [CrossRef]

12. Frenken, K. Sustainability perspectives on the sharing economy. Environ. Innov. Soc. Trans. 2017, 23, 1-2. [CrossRef]

13. Frenken, K.; Schor, J. Putting the sharing economy into perspective. Environ. Innov. Soc. Trans. 2017, 23, 3-10. [CrossRef]

14. Tukker, A. Product services for a resource-efficient and circular economy-A review. J. Clean. Prod. 2015, 97, 76-91. [CrossRef]

15. Amasawa, E.; Suzuki, Y.; Moon, D.; Nakatani, J.; Sugiyama, H.; Hirao, M. Designing interventions for behavioral shifts toward product sharing: The case of laundry activities in Japan. Sustainability 2018, 10, 2687. [CrossRef]

16. Frenken, K. Political economies and environmental futures for the sharing economy. Phil. Trans. R. Soc. A 2017, 375, 20160367. [CrossRef] [PubMed]

17. McDonald, S.; Oates, C.J.; Young, C.W.; Hwang, K. Toward sustainable consumption: Researching voluntary simplifiers. Psychol. Market. 2006, 23, 515-534. [CrossRef]

18. Hawlitschek, F.; Stofberg, N.; Teubner, T.; Tu, P.; Weinhardt, C. How corporate sharewashing practices undermine consumer trust. Sustainability 2018, 10, 2638. [CrossRef]

19. Vaskelainen, T.; Piscicelli, L. Online and offline communities in the sharing economy. Sustainability 2018, 10, 2927. [CrossRef]

20. Sabitzer, T.; Hartl, B.; Marth, S.; Hofmann, E.; Penz, E. Preventing conflicts in sharing communities as a means of promoting sustainability. Sustainability 2018, 10, 2828. [CrossRef]

21. Leismann, K.; Schmitt, M.; Rohn, H.; Baedeker, C. Collaborative consumption: Towards a resource-saving consumption culture. Resources 2013, 2, 184-203. [CrossRef] 
22. Mont, O.; Neuvonen, A.; Lähteenoja, S. Sustainable lifestyles 2050: Stakeholder visions, emerging practices and future research. J. Clean. Prod. 2014, 63, 24-32. [CrossRef]

23. Ter Huurne, M.; Ronteltap, A.; Guo, C.; Corten, R.; Buskens, V. Reputation effects in socially driven sharing economy transactions. Sustainability 2018, 10, 2674. [CrossRef]

24. Akyelken, N.; Banister, D.; Givoni, M. The sustainability of shared mobility in london: The dilemma for governance. Sustainability 2018, 10, 420. [CrossRef]

25. Philp, M.; Taylor, M.A.P. Research agenda for low-carbon mobility: Issues for new world cities. Int. J. Sustain. Transp. 2017, 11, 49-58. [CrossRef]

26. Heinrichs, H. Sharing economy: A potential new pathway to sustainability. GAIA-Ecol. Pers. Sci. Soc. 2013, 22, 228-231. [CrossRef]

27. Liu, Y.; Yang, Y. Empirical examination of users' adoption of the sharing economy in China using an expanded technology acceptance model. Sustainability 2018, 10, 1262. [CrossRef]

28. Wu, X.; Shen, J. A study on airbnb's trust mechanism and the effects of cultural values—Based on a survey of Chinese consumers. Sustainability 2018, 10, 3041. [CrossRef]

29. Dempsey, N.; Bramley, G.; Power, S.; Brown, C. The social dimension of sustainable development: Defining urban social sustainability. Sustain. Dev. 2011, 19, 289-300. [CrossRef]

30. Kang, S.; Na, Y. The effect of the relationship characteristics and social capital of the sharing economy business on the social network, relationship competitive advantage, and continuance commitment. Sustainability 2018, 10, 2203. [CrossRef]

31. Hartl, B.; Hofmann, E.; Kirchler, E. Do we need rules for 'what's mine is yours'? Attitudes towards governance in collaborative consumption. J. Bus. Res. 2016, 69, 2756-2763. [CrossRef]

32. Hofstede, G. Culture's Consequences: International Differences in Work-Related Values; Sage: Newbury Park, CA, USA, 1984; Volume 5.

33. Gollnhofer, J.F.; Schouten, J.W. Complementing the dominant social paradigm with sustainability. J. Macromarket. 2017, 37, 143-152. [CrossRef]

34. Latitude. The New Sharing Economy; Latitude: Beverly, MA, USA, 2018.

35. Cohen, B.; Muñoz, P. Sharing cities and sustainable consumption and production: Towards an integrated framework. J. Clean. Prod. 2016, 134, 87-97. [CrossRef]

36. Zervas, G.; Proserpio, D.; Byers, J.W. The rise of the sharing economy: Estimating the impact of airbnb on the hotel industry. J. Market. Res. 2017, 54, 687-705. [CrossRef] 